\title{
Factors that Determine Advertising Evasion in Social Networks
}

\section{Autores}

Jesús Silva, Yisel Pinillos-Patiño, Harold Sukier, Jesús Vargas, Patricio Corrales, Omar Bonerge Pineda Lezama, Benjamín Quintero

\begin{abstract}
The present work is framed within the study of advertising evasion online and particularly in social networks. Social networks are a growing phenomenon, where users spend most of their time online and where companies are moving part of their advertising investment, as they are considered an ideal place for commercial campaigns. In order to deepen in the variables that precede advertising evasion in social networks, a relationship model was developed based on the theoretical framework of advertising evasion on the Internet, which was contrasted at an empirical level through a panel of users. For this purpose, a structural equation model was designed, which highlighted the relationships between the main antecedent variables of evasion, such as perceived control, advertising intrusion, and psychological reaction.
\end{abstract}

Palabras clave

Perceived control, Intrusion, Reactance, Advertising evasion, Social networks 